\title{
QUANTITATIVE STRUCTURE-ACTIVITY RELATIONSHIP AND MOLECULAR DOCKING STUDIES OF HYDROXAMIC ACID DERIVATIVES AS NOVEL CLASS INHIBITORS AGAINST HELICOBACTER PYLORI UREASE
}

\author{
I. T. IBRAHIM ${ }^{1 *}$, A. UZAIRU ${ }^{2}$ and B. SAGAGI ${ }^{1}$ \\ ${ }^{1}$ Department of Chemistry, Kano University of Science and Technology, Wudil Kano, Nigeria \\ ${ }^{2}$ Department of Chemistry, Ahmadu Bello University Zaria, Kaduna, Nigeria \\ Email: tibrahim1832@gmail.com
}

\begin{tabular}{l} 
A R T I C L E I N F O \\
\hline Article history: \\
Received 2019-09-06 \\
Accepted 2019-12-20 \\
Available online 2019-12-20 \\
key words \\
QSAR \\
Molecular Docking \\
DFT, GFA \\
Ulcer \\
1E9Y hydrolase
\end{tabular}

\section{INTRODUCTION}

Helicobacter pylori ( $H$. pylori - parasite) is a class of bacteria and be the most causative agent of gastric issue around the globe mostly in the underdeveloped and developing countries (Ezealisiji, et al, 2014). The urease enzyme of Helicobacter pylori causes infections of gastrointestinal and urinary tract disorder, about half of the world population was engaged with the bacterial parasite, as a consequence of peptic ulcer the statistical analysis reported that about 15, 000 deaths annually (Sharma \& Bhatt, 2014). The influence of a constitutive urea amidohydrolase enzyme given out the amount of ammonia compound release by the hydrolysis result in the enhancement of medium and creates friendly environment for the survival of Helicobacter pylori (Amtul, et al., 2002). These bacterial parasite secrete a fluid substances called VaCA (Vacuolating cytotoxin autotransporter) and has cytotoxic effects including mitochondrial damage and apoptosis (Yamasaki et al., 2006). The existing of H.pylori in gastric mucosa cavity lead in the increment of serious gastritis progresses with intolerable distressing pain, gastritis forward to give a network of complication such as gastric ulcer, gastric neoplasia problem and some distinct gastric confusion (Radin et al., 2014). VacA provides an anionic stream on the plasma boundary, these micro-channel are very significant for coming number of germs into the cavity of the cells and vacuole formed in a epithelial cell of $H$. pylori (Chey et al, 2001). VacA release by bacteria inform of protein of $88 \mathrm{kDa}$ and can cause membrane depolarization, change of mitochondrial membranes permeability, protein kinase mitogen-activated, interactions with immune system, inhibition of $\mathrm{T}$ cell activation, detachment of cell from basement membranes permeability proliferation and VacA given rise to cell death in the infected tissue (Simmons., 2010).

A decades ago the common treatment of $H$. pylori parasite were that, infected persons regularly use bismuth compound and proton pump inhibition (PPI) within a long period of time (Sachs et al., 2005). This suggestion of the treatment was not safe for simultaneous use of PPIs because its deviate from working positive toward the treatment of ulcer disease and lead negative result for gastric analysis disorder. Antibiotic is also found to be cause drugs resistance (Stingl et al., 2002). So, these lead the researchers moving deep, seeking novel and best drug candidate to treat gastro-infection disease. 
Similarly, the inhibitions of amidohydrolase enzyme is taken for a good chance to treat infection cause by Helicobacter pylori parasite (Saeed et al., 2014). Decades ago, about thousands of urease enzyme inhibitors were identified such as benzo[d]thaizole hydrazone, phosphoramidate, urea analogues, hydroxamic acids, chromanones, polyphenols and alkaniod (Vassiliou et al., 2010). It was found that phosphoramidate are the most active but not marketed as drug, this influence by quick hydrolysis ( addition water molecules) in low $\mathrm{pH}$ value of gastric juice colorless acid fluid (which has a capable to donate proton) secreted by stomach gland (Zhang et al., 2011).

Among all these compounds above hydroxamic acid has an important to attract or form a bond between two or more molecule properly, including to form very tired complexes bond with the different of transition metal ions and normally its involved binding metal ions of active to inactive side of the urease enzyme, for that, hundreds of hydroxamic acid compound are found to be possible agent and play a vital role to treat H.pylori infection (Xiao et al., 2013). Acetohydroxamic acid compound (AHAC) was the best studied urease (amidohydrolase) inhibitor (Xiao et al., 2007). Flavenes (Wang et al., 2015), flavonoid (Xiao et al., 2013), furan-2 (5H)-one (Kubo et al., 1999) and 1, 2 diarylethane (Xiao et al., 2012), were reported as potent urease inhibitors.

QSAR was developed in 1868 by Alexander Crum-Brown and R. Fraser (Kubinyi, 1993), they worked and published a scientific equation which is considered to be the initial general approach of a quantitative activity relationship studies, different alkaniod recognized alkylation of the basic nitrogenous atoms produces meaningful different biological effect of the obtaining permanently charged quaternary ammonium compound, as compared to the basic amines candidate, then they assume that, physiological activity character must be a parameter of the chemical structure (Puzyn et al., 2010). Hence, QSAR refers to an approach for building in silico or mathematical which shot to find a statistically important relationship between the structure and function using chemometric techniques. The main achievement of QSAR approach is the chance of evaluating the properties of novel chemical compound or molecule with needless of synthesis or testing in the lab.

Formal development of relationships on these promises, found to be the pillar for the advancement of prophetic models. It takes a number of chemicals compound and try to form a quantitative relationship (QRs) between the biological effects (BE) activity and chemistry of each chemical structure, then able to form quantitative structure activity relationship approach (QSARA).

Both structure of the compound and biological activity must be quantified, while biological activity can be measured in quantitative terms, nevertheless, it is not easy to quantify the structure, but in this junction, QSAR use to quantify the chemical structure of the compound and express it, in term of physico-chemical features and measured easily as well as accurately. This include examples of; partition coefficient, pKa, spectral properties, steric characters etc. (Yap, 2011). The molecular docking technique was first applied to biology which determine the interaction of sickle hemoglobin. Molecular docking is the process that involves placing the molecule in an appropriate configuration to interact with a receptor protein. Or also express as; molecular docking is a natural process which occurs within seconds in a cell, when bond to each other to form stable complex. Today In silico and molecular docking approach return over 5000 articles by the year 2016 alone which over 3000 research papers are linked to design a number of compounds (Veerasamy et al., 2011). The significance of this research approach was to develop the QSAR (In silico) model using Genetic Function Algorithms approach and envisage the enzyme compound's inhibitory activity. All 24 ligands (hydroxamic acid analogues) docked with the receptor protein of $1 \mathrm{E} 9 \mathrm{Y}$.

\section{MATERIAL AND METHOD}

All twenty-four candidates of hydroxamic acid analogues takes as antiulcer activity which obtained from the literature and used in the study. Antiulcer compounds activity was measured as $\mathrm{pED}_{50}(\mu \mathrm{M})$ and expressed in form of log-scale as $\mathrm{pED}_{50}$ $\left(\mathrm{pED} 50=\log 1 / \mathrm{ED}_{50}\right)$ and presents it, as dependent variables, accordingly linking the data linearly together with independent descriptors variable. The main structure together with the biological activities of these molecules are shown in Table 1.

\subsection{Computational Molecular Modeling}

Spartan'14 v1.1.0 software, were used to obtain molecular modeling of 24 molecules (hydroxamic acid derivatives) and PaDEL software descriptor version successively using Dell satellite, Microsoft windows 8.1 operating system, with Intel corei5 Dual CPU @2.50 and 8GB of RAM. The molecular structure of the hydroxamic acid molecular compounds were drawn by Chem Draw software. All 24 compounds drawn in 2D and transmute in to 3D format which geometrically optimized to minimize the energy. Structural electronic analysis calculation and extra descriptors properties of hydroxamic acid derivatives achieved using density functional theory by B3LYP - 6-31G*. All the compounds optimized from Spartan '14 software and saved inform of sdf which later transfer to PaDEL- descriptor package version tools to provide a meaningful calculation of $2 \mathrm{D}$ and $3 \mathrm{D}$ descriptors respectively (Malik et al., 2013). 
<smiles>[R]c1c([R])c([2H])c([R])c(C(O)CC(=O)N([R])O)c1[R]</smiles>

Figure 1- Structure of the main compound $R_{1-} R_{4}$ are substituent in the table 1 below.

Table 1. Training sets are shown with ' $x$ ' while test sets are shown with ' $y$ '

\begin{tabular}{|c|c|c|c|c|c|c|c|c|}
\hline S/NO & $\mathbf{R}$ & $\mathbf{R}_{\mathbf{1}}$ & $\mathbf{R}_{\mathbf{2}}$ & $\mathbf{R}_{\mathbf{3}}$ & $\mathbf{R}_{4}$ & $\begin{array}{l}\text { pIC50}_{50}(\mathbf{M}) \\
\text { Activity }\end{array}$ & Pred.pED50 & Residue \\
\hline $1 \mathrm{y}$ & $\mathrm{Me}$ & $\mathrm{Cl}$ & $\mathrm{H}$ & $\mathrm{H}$ & $\mathrm{H}$ & 4.25 & 4.06 & 0.19 \\
\hline $2 \mathrm{x}$ & $\mathrm{Me}$ & $\mathrm{OMe}$ & $\mathrm{H}$ & $\mathrm{H}$ & $\mathrm{H}$ & 4.07 & 4.54 & -0.47 \\
\hline $3 x$ & $\mathrm{Me}$ & $\mathrm{H}$ & $\mathrm{F}$ & $\begin{array}{ll}\mathrm{H} \\
\end{array}$ & $\mathrm{H}$ & 4.15 & 4.14 & 0.01 \\
\hline $4 y$ & $\mathrm{Me}$ & $\mathrm{H}$ & $\mathrm{Cl}$ & $\mathrm{H}$ & $\mathrm{H}$ & 4.32 & 4.07 & 0.26 \\
\hline $5 x$ & $\mathrm{Me}$ & $\mathrm{H}$ & $\mathrm{Br}$ & $\mathrm{H}$ & $\mathrm{H}$ & 4.10 & 4.07 & 0.04 \\
\hline $6 \mathrm{x}$ & $\mathrm{Me}$ & $\mathrm{H}$ & $\mathrm{OMe}$ & $\mathrm{H}$ & $\mathrm{H}$ & 4.05 & 4.06 & -0.01 \\
\hline $7 y$ & $\mathrm{Me}$ & $\mathrm{H}$ & $\mathrm{H}$ & $\mathrm{F}$ & $\mathrm{H}$ & 4.11 & 4.07 & 0.04 \\
\hline $8 \mathrm{x}$ & $\mathrm{Me}$ & $\mathrm{H}$ & $\mathrm{H}$ & $\mathrm{Cl}$ & $\mathrm{H}$ & 4.06 & 4.06 & 0.00 \\
\hline $9 \mathrm{x}$ & $\mathrm{Me}$ & $\mathrm{H}$ & $\mathrm{H}$ & $\mathrm{Br}$ & $\mathrm{H}$ & 4.01 & 4.06 & -0.05 \\
\hline $10 \mathrm{y}$ & $\mathrm{Me}$ & $\mathrm{H}$ & $\mathrm{H}$ & $\mathrm{OMe}$ & $\mathrm{H}$ & 3.48 & 3.32 & 0.16 \\
\hline $11 \mathrm{x}$ & $\mathrm{Me}$ & $\mathrm{H}$ & $\mathrm{H}$ & $\mathrm{N}(\mathrm{CH} 3) 2$ & $\mathrm{H}$ & 3.54 & 3.55 & -0.01 \\
\hline $12 \mathrm{x}$ & $\mathrm{Me}$ & $\mathrm{H}$ & $\mathrm{H}$ & $\mathrm{OBn}$ & $\mathrm{H}$ & 3.70 & 3.68 & 0.02 \\
\hline $13 y$ & $\mathrm{Me}$ & $\mathrm{Cl}$ & $\mathrm{Cl}$ & $\mathrm{H}$ & $\mathrm{H}$ & 4.02 & 3.96 & 0.06 \\
\hline $14 \mathrm{x}$ & $\mathrm{Me}$ & $\mathrm{Cl}$ & $\mathrm{H}$ & $\mathrm{Cl}$ & $\mathrm{H}$ & 3.44 & 3.44 & 0.00 \\
\hline $15 \mathrm{x}$ & $\mathrm{H}$ & $\mathrm{Cl}$ & $\mathrm{H}$ & $\mathrm{Cl}$ & $\mathrm{H}$ & 4.87 & 4.88 & -0.01 \\
\hline $16 y$ & $\mathrm{Me}$ & $\mathrm{Cl}$ & $\mathrm{H}$ & $\mathrm{H}$ & $\mathrm{Cl}$ & 4.11 & 3.42 & 0.69 \\
\hline $17 \mathrm{x}$ & $\mathrm{Me}$ & $\mathrm{H}$ & $\mathrm{Cl}$ & $\mathrm{Cl}$ & $\mathrm{H}$ & 4.03 & 4.02 & 0.01 \\
\hline $18 \mathrm{x}$ & $\mathrm{Me}$ & $\mathrm{H}$ & OBn & OBn & $\mathrm{H}$ & 3.42 & 3.45 & -0.03 \\
\hline $19 y$ & $\mathrm{Me}$ & $\mathrm{H}$ & $\mathrm{OMe}$ & OBn & $\mathrm{H}$ & 3.59 & 3.75 & -0.16 \\
\hline $20 \mathrm{x}$ & $\mathrm{Me}$ & $\mathrm{H}$ & $\mathrm{OMe}$ & $\mathrm{OMe}$ & $\mathrm{H}$ & 3.39 & 3.32 & 0.07 \\
\hline $21 x$ & $\mathrm{Me}$ & $\mathrm{H}$ & $\mathrm{Cl}$ & $\mathrm{H}$ & $\mathrm{OH}$ & 4.52 & 4.52 & 0.00 \\
\hline $22 y$ & $\mathrm{H}$ & $\mathrm{H}$ & $\mathrm{Cl}$ & $\mathrm{H}$ & $\mathrm{OH}$ & 5.96 & 6.09 & -0.13 \\
\hline $23 x$ & $\mathrm{Me}$ & $\mathrm{H}$ & $\mathrm{Cl}$ & $\mathrm{H}$ & OBn & 4.58 & 4.57 & 0.01 \\
\hline $24 x$ & $\mathrm{H}$ & $\mathrm{H}$ & $\mathrm{Cl}$ & $\mathrm{H}$ & $\mathrm{OBn}$ & 6.82 & 6.81 & 0.01 \\
\hline
\end{tabular}

\subsection{Insilico-Method}

The validated QSAR models can be obtain by using descriptors (D series), which generated by the PaDEL software version (Kennard \& Stone., 1969) and Spartan'14 software, the descriptors of 2D and 3D were divided into two different class of training $(70 \%)$ and test $(30 \%)$ sets. The training (internal validation) set have been used to generate the model, while the test (external) set of the model. In this study, the Kennard-Stone algorithm (KSA) were used to perform the division and calculates the inter-sample distance matrix ones (Khaled, 2011). The procedures deployed in dividing the datasets into two different training and test sets using dataset software Division
GUl 1.2 program are highlighted thus: dataset Division GUl 1.2. The relation between activity values against the protein enzyme (1E9Y) and chemical descriptors have been calculated and was obtained from correlation analysis using material studio software, selected the suitable descriptors for regression statistics have been done by taking Pearson's product-moment correlation matrix $(\mathrm{pcm})$ as quantitative model. The descriptors generated from PaDEL software version, "Kennard \& Stone", (1969) were subjected to regression analysis with experimental activities of dependent variables and also selected chemical descriptors as independent variable using the technique of Genetic Function Algorithms (GFA) in material studio software machine. The regression equation of descriptors is 5 , population and maximum 
generation are presented as 500 and 1000 correspondingly. The number of scaled LOF smoothness parameter is 0.5 , number of maximum equation length is 5 , and mutation probability is 0.1 . Generic Function Algorithm techniques selecting the basic function generally developed good models than others made using proceeding a stage regression method, the model was assessed using LOF were measured using a slight variation of the original Friedman formula, this come to chance, the best fitness score can be received. The revised formula of LOF (Wang et al., 2015) follow:

$L O F=\frac{S S E}{\left(1-\frac{C+d p}{M}\right)^{2}}$

Where SSE is the sum of square errors or sum of square residual $\mathrm{SSR}, c$ is the number of terms in the model, other than the constant terms, $d$ is a user defined smoothing parameter, $p$ is the total number of descriptors enclosed in all model terms (ignoring the constant term) and $M$ is the number of sample in the training set unlike the commonly used least squares measure (LSM), LOF measure cannot always be reduced by adding more terms to the regression model. While the new terms will reduce the SSE at the time, it increases the value of $c$ and $d$ which give chance to increase the LOF score. By limiting the tendency to simple more terms, the LOF measure resist over fitting better than the SSE measure (Material Studio 8.0 guide).

\subsection{Quality Assurance Validations}

Internal and external validation parameters were used to develop the consistency and predicted ability of the QSAR model. The validation parameters have compared with the minimum recommended values for a generally acceptable QSAR model as shown in Table 2.

(a) Square of the correlation coefficient $\left(\boldsymbol{R}^{2}\right)$ : Describes the friction of the total variation recommended to the model. The closer the value of $R^{2}$ is to 1.0 , the better the regression equation explains in $\mathrm{Y}$ variable. $R^{2}$ is the most normally used internal validation and express as the following:

$$
\mathrm{R}^{2}=1-\frac{\sum(\text { Yobserved }- \text { Ypredicted })^{2}}{\sum(\text { Yobserved }- \text { Ytraining })^{2}}
$$

Table 2 Minimum recommended value for the evaluation of the quantitative QSAR model. (Bramhane et al., 2016)

\begin{tabular}{lllc} 
S/N & Symbol & Name & Value \\
1 & $\mathrm{R}^{2}$ & Square correlation coefficient & $\geq 0.6$ \\
2 & $\mathrm{Q}^{2}$ & Cross validation coefficient & $>0.5$ \\
3 & $\mathrm{R}_{\text {pred }}^{2}$ & Square correlation coefficient - external set & $\geq 0.6$ \\
4 & $\mathrm{R}_{\text {adj }}^{2}$ & Adjusted square correlation coefficient & $\leq 0.5$ \\
5 & $\mathrm{P}(95 \%)$ & Confidence interval at $95 \%$ & $\leq 0.05$ \\
6 & Next test set & Minimum number of extend test set & $\geq 5$ \\
7 & $\mathrm{R}^{2}-\mathrm{Q}^{2}$ & Difference between $\mathrm{R}^{2}$ and $\mathrm{Q}^{2}$ & $\leq 0.3$ \\
\hline
\end{tabular}

Various internal validation parameters that have been used in this study are untaken thus:

Where Yobs; Ypred; and Ytraining are presented as experimental, mean experimental predicted and the property of the sample's training set respectively (Bramhane et al., 2016).

(b) Adjusted $\mathbf{R}^{\mathbf{2}}$ ( $\mathbf{R}^{\mathbf{2}}$ adj): The descriptors repressor's number increase directly and differs the $\mathrm{R}^{2}$ value, similarly $\mathrm{R}^{2}$ cannot be usefully measure for the goodness of model fitness. Then, $\mathrm{R}^{2}$ is adjusted for the numerical number of clarifying variables in the model. The adjusted $\mathrm{R}^{2}$ value express as:

$R_{\text {adj }}^{2}=\left(1-R^{2}\right) \frac{N-1}{N-P-1}=\frac{(N-1) R^{2}-P}{N-P+1}$

Where $\mathrm{p}=$ number of independent variables in the model and $\mathrm{N}$ = sample size (Wang et al., 2015).

(c) Leave one out cross validation coefficient $\left(\mathbf{Q}^{2}\right)$ : The LOO cross validated coefficient $\left(\mathrm{Q}^{2}\right)$ is given by;

$Q^{2}=1-\frac{\sum(Y p-Y)^{2}}{\sum(Y-Y m)^{2}}$
Where Yp and Y represent the predicted and observed activity of the training set and $\mathrm{Y}_{\mathrm{m}}$ the mean activity value of the training set.

In this point, by testing the previous excluded compounds which form the test set, the models will be superficially validated. The value of $\mathrm{R}^{2}$ Pred which gives an indication of the predictive power of a model have calculated by equation 5 (Monika \& Singh, 2013).

$R_{\text {pred }}^{2}=\frac{\sum[\text { Ypred }(\text { test })-\text { Yobserved }(\text { test })]^{2}}{\sum[\text { Yobserved }(\text { test })-\text { Ymean }(\text { training })]^{2}}$

$\mathrm{Y}_{\text {pred. }}$ (test) and $\mathrm{Y}_{\text {observed }}$ (test) indicate observed and predicted activity values respectively of the test set compounds and $Y_{\text {mean }}$ (training) designates mean activity value of the training.

\subsection{Applicability Domain}

Applicability domain (AD) of a QSAR model is the physicochemical, structure or biological space or information on which the training set of the model has been developed and applicable to make prediction for new compound. The model was validated using Williams plot, and it's presented as standardized residuals by the leverages Figure 2 below. 
This method exploited to visualize the applicability domain (AD). Leverage indicates a molecules distance from the centroid of X. (Trott \& Olson, 2010). The leverage of molecule in the original space is defined as;

$h_{i}=X_{i}^{T}\left(X^{T} X\right)^{-1} X_{i}$

Where $x i$ is the descriptor vector of the considered molecule $\mathrm{X}$, the descriptor matrix derived from the training set descriptor values.
The leverage $\left(h^{*}\right)$ is defined as:

$h^{*}=\frac{3(p+1)}{n}$

Where $\mathrm{n}=$ Number of training set

$\mathrm{P}=$ Number of descriptors in a test set

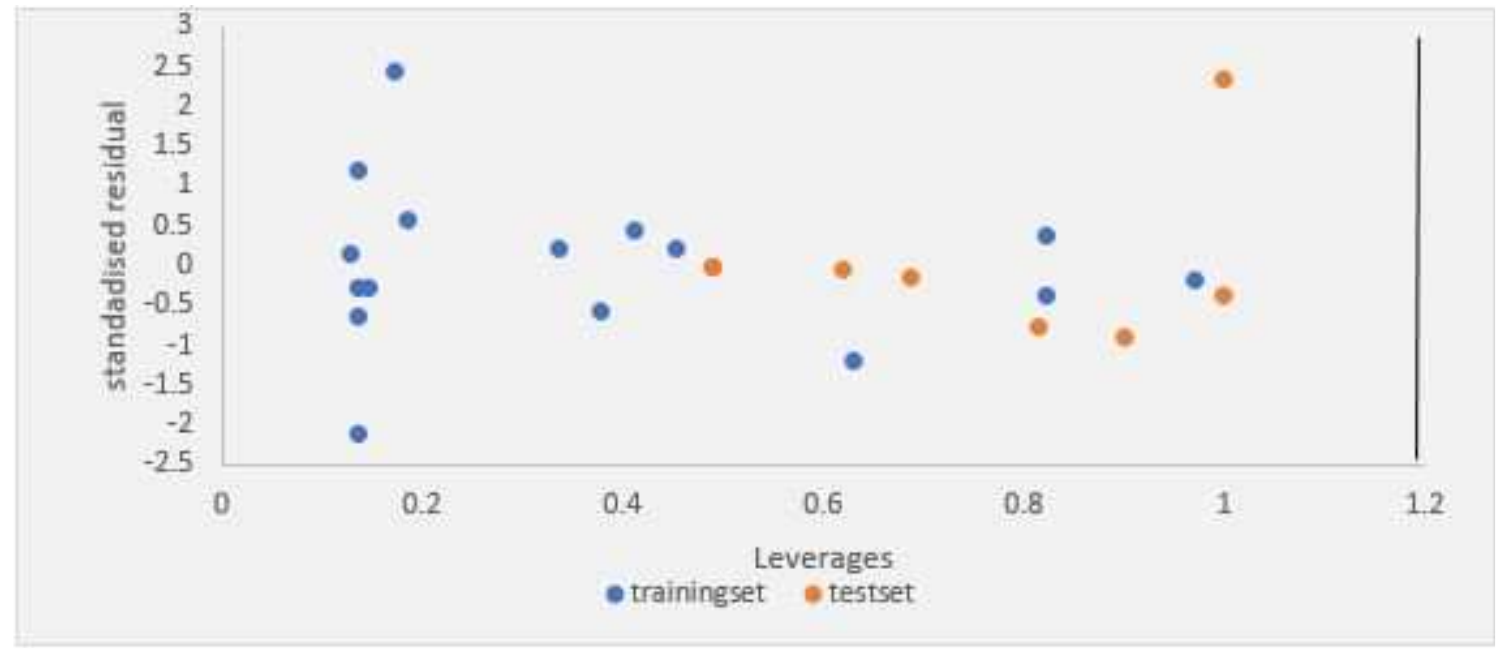

Figure - 2 Williams plot.

The above graph (Williams plot, Figure. 2) shows that all the molecules of training and test set fall within the domain of GFA model (Leverages of $\mathrm{h}^{*}=1.25$ ), the plot also shows that, blue dot indicate training set molecules while the lightbrown dot indicate test set molecules no any molecule found structural outliers.

\subsection{Molecular Docking study}

\section{Docking tools}

Docking preparation and energy calculation's unit given as $(\mathrm{kcal} / \mathrm{mol})$ of active antiulcer molecule compounds and enzyme of 1E9Y were executed by Molecular Graphics Laboratory (GML) tools software and Automatic Docking Vina of PyRx software (Kumar et al, 2010). Pre-calculation Autogrid molecular docking of antiulcer molecules was achieved by Autodock Vina-Pyrx software and explaining the target point 1E9Y receptor protein. Energy grid was enrolled based on the method of Lamarckian Genetic Algorithm (Chen et al., 2017). Chimera software, discovery studio software version 3.5, Ligplot and visualization PyMol software were used to perform the virtual analysis of (interaction between the molecules and the enzyme) docking site.

\subsection{Preparation of the target enzyme}

The structure of 1E9Y receptor protein inform of 3D, was extracted from the website of protein data bank in PDB format. All hetero-atomic molecules were excluded from the folder using Discovery Studio version 3.5 software, hydrogen was added to the receptor (Fig. 3a) and removed water ( Fig. 3b) from the 3D enzyme structure, by using discovery studio software. The receptor enzyme (1E9Y) inform of 3D was minimized, protonated and saved in pdbqt format in all polar residues.

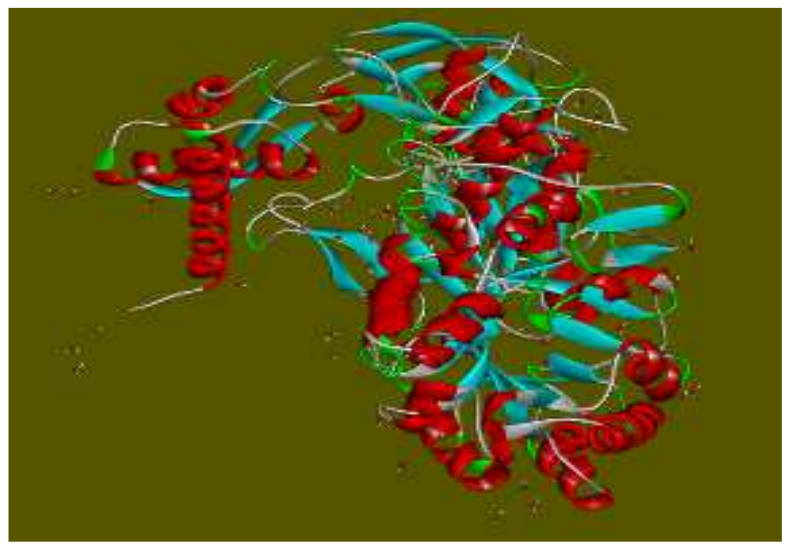

Figure 3a - 1E9Y Receptor after adding hydrogen atom. 


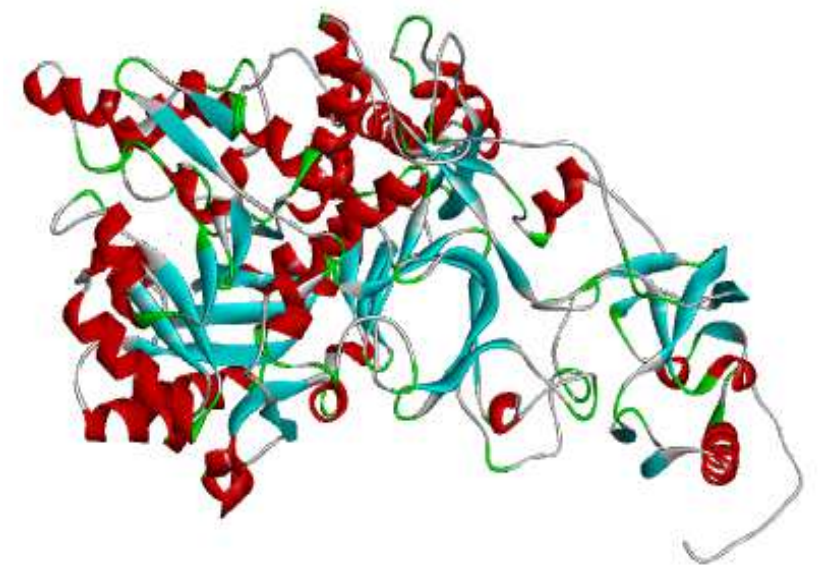

Figure 3b - 1E9Y Receptor after adding hydrogen and removed water.

\subsection{Preparation of the ligands}

All twenty four (24) molecules of hydroxamic acid analogues (Table 1) used as ligands were selected from the literature (Chen et al., 2017). ChemDraw Pro 12.0.1V software used and draw the 2D structure of hydroxamic acid analogues and then transformed to 3D structures, optimized and kept in pdb file format by Spartan'14 software version1.1.2 (Abdulfatai et al., 2019). The compounds also transformed to pdbqt format by Autodock 4.2 machine software, the prepared ligand inform of $3 \mathrm{D}$ is shown in Figure 4.



Figure 4 - Ligand structure.

\section{RESULTS AND DISCUSSION}

QSAR studies

In these studies, five developed QSAR models were obtained and recoded, one out of five models found and marked to be the best model (Model 3), due to statistics significance parameters. The developed model 3 shown (Table 3), both names and symbol descriptors used in the optimization model. And also shown the second (Table 4) for the validation result of the GFA of model 3, which generated from the material studio machine software. The best QSAR model 3 developed has fulfilled the minimum recommendation value of validation measures for acceptable QSAR model (Veerasamy et al., 2011).

These are five models constructed from the results obtained;

Model 1

$\mathrm{Y}=2.138480743 *$ MATS7c $-0.395118752 *$ VE3_Dze + $1.213719777 *$ SHBd $+0.655284270 * \operatorname{maxHBint} 5$ $0.374056826 *$ piPC10 $-1.85511, N=16 R^{2}=0.99945200$, $R^{2}{ }_{A D J}=0.99917700, Q^{2}=0.99735800$ and $R_{P R E D}^{2}=1, L O F=$ 0.00285300, Significance-of-regression F-value = $3.644376 \mathrm{e}+003$

\section{Model 2}

IC50 $=2.200238051 *$ MATS7c $-0.402279837 *$ VE3_Dze $+1.194215591 * \mathrm{SHBd}-0.543409743 * \operatorname{minsCH} 3$ $0.407294756 * \operatorname{piPC} 10+3.388758, N=16 R^{2}=(0.9989)$, $R_{\text {ADJ }}^{2}=0.9984, Q^{2}=0.9973$ and $R_{\text {PRED }}^{2}=0.8348, L O F=$ 0.00541800, Significance-of-regression F-value = $1.917642 \mathrm{e}+003$

\section{Model 3}

IC50 $=2.190373567 *$ MATS7c $-0.401616495 *$ VE3_Dze $+1.244306389 * \mathrm{SHsOH}-1.530674355 *$ nAtomLC $0.403952507 * \operatorname{piPC} 10+14.8935, N=16 R^{2}=(0.9989)$, $R_{\mathrm{ADJ}}^{2}=0.9984, Q^{2}=0.9948$ and $R^{2}{ }_{\text {PRED }}=0.8409, L O F=$ 0.00564400 , Significance-of-regression F-value = $1.840798 \mathrm{e}+003$

Model 4

$\mathrm{Y}=2.189844538 *$ MATS7c $-0.400048053 *$ VE3_Dze $259.745686012 *$ BCUTc- $1 \mathrm{~h}+1.244451234 *$ SHBd $0.396291231 *$ piPC10 + 61.82555, $N=16 R^{2}=0.99891000$, $R^{2}{ }_{A D J}=0.99836500, Q^{2}=0.99484500$ and $R_{P R E D}^{2}=$ $0.837813, L O F=0.00566700$, Significance-of-regression Fvalue $=1.833311 \mathrm{e}+003$

\section{Model 5}

$\mathrm{Y}=2.185859559 *$ MATS7c $-0.396683253 *$ VE3_Dze $630.096723785 *$ BCUTc-1h $+1.243846320 * \mathrm{SHsOH} \quad-$ $0.384273822 * \operatorname{piPC} 10+146.2024, N=16 R^{2}=0.99891000$, $R^{2}{ }_{A D J}=0.99836500, Q^{2}=0.99502300$ and $R^{2}{ }_{P R E D}=$ $0.838282, L O F=0.00566900$, Significance-of-regression Fvalue $=1.832695 \mathrm{e}+003$ 
Table 3. Physicochemical numbers of descriptor used in the best model 3

\begin{tabular}{lllll}
\hline S/No & Symbol & Name of descriptors & Class \\
\hline 1 & MATS7c & Moran autocorrelation - Lag 7/ weight by charges & 2D \\
2 & VE3_Dze & Logarithmic Randic-Like eigenvector-based index from barynsz matrix/ weighted by & 2D \\
& & sanderson electronegative & 2D \\
3 & ShsOH & Sum of atom-type E- state: OH & 2D \\
4 & nAtomLC & Number of atoms in the large chain & 2D \\
5 & piPC10 & Molecular multiple path count of order 10 & \\
\hline
\end{tabular}

\section{Table 4. Genetic function approximation (GFA) output - validation from material studio}

\begin{tabular}{|c|c|c|c|c|c|}
\hline Equations & Equation 1 & Equation 2 & Equation 3 & Equation 4 & $\begin{array}{l}\text { Equation } \\
5\end{array}$ \\
\hline Friedman LOF & 0.002853 & 0.005418 & 0.005644 & 0.005667 & 0.005669 \\
\hline R-squared & 0.999452 & 0.998958 & 0.998915 & 0.99891 & 0.99891 \\
\hline Adjusted R-squared & 0.999177 & 0.998437 & 0.998372 & 0.998365 & 0.998365 \\
\hline Cross validated R-squared & 0.997358 & 0.996993 & 0.994818 & 0.994845 & 0.995023 \\
\hline Significant Regression & Yes & Yes & Yes & Yes & Yes \\
\hline Significance-of-regression F-value & $3.64 \times 10^{3}$ & $1.92 \times 10^{3}$ & $1.84 \times 10^{3}$ & $1.83 \times 10^{3}$ & $1.83 \times 10^{3}$ \\
\hline Critical SOR F-value (95\%) & 3.345145 & 3.345145 & 3.345145 & 3.345145 & 3.345145 \\
\hline Replicate points & 1 & 1 & 1 & 1 & 1 \\
\hline Computed experimental error & 0.064031 & 0.064031 & 0.064031 & 0.064031 & 0.064031 \\
\hline Lack-of-fit points & 9 & 9 & 9 & 9 & 9 \\
\hline $\begin{array}{l}\text { Min expt. error for non-significant } \\
\text { LOF }(95 \%)\end{array}$ & 0 & 0 & 0 & 0 & 0 \\
\hline
\end{tabular}

Table 5. Molecular docking interactions with the inhibitors, docking scores and active site residues involved

\begin{tabular}{|c|c|c|c|c|}
\hline Ligand & $\begin{array}{l}\text { Binding } \\
\text { Energy }\end{array}$ & Residual interaction & Hydrogen bond interaction & Hydrogen bond distance \\
\hline 1 & -6.6 & $\begin{array}{l}\text { PHE441, TYR32, LYS445, } \\
\text { VAL33, VAL36, VAL473 }\end{array}$ & $\begin{array}{l}\text { GLN459, TYR475, TYR475, } \\
\text { LYS445, ASN447, GLN459 }\end{array}$ & $\begin{array}{l}2.98882,1.91467,2.45092,2.1185, \\
3.66931,3.56078\end{array}$ \\
\hline 2 & -5.9 & & $\begin{array}{l}\text { LYS394, ASN397, PHE400, } \\
\text { LYS394, ASN397, LYS394, } \\
\text { LYS394 }\end{array}$ & $\begin{array}{l}2.17768,2.12254,2.75902, \\
3.00611,1.9396,3.36585,3.79581\end{array}$ \\
\hline 3 & -6.7 & $\begin{array}{l}\text { PHE441, TYR32, VAL33, } \\
\text { VAL36, VAL473 }\end{array}$ & $\begin{array}{l}\text { GLN459, TYR475, PRO446, } \\
\text { TYR32, ASN447 }\end{array}$ & $\begin{array}{l}2.78761,2.18635,2.52611, \\
2.2497,3.54086\end{array}$ \\
\hline 4 & -6.2 & $\begin{array}{l}\text { CYS321, MET366, ALA365, } \\
\text { MET317, MET366, ALA365 }\end{array}$ & $\begin{array}{l}\text { NI3001, NI3002, ALA169, } \\
\text { HIS221, ALA169 }\end{array}$ & $\begin{array}{l}2.43694,3.34171,2.90556, \\
1.91897,2.88251\end{array}$ \\
\hline 5 & -6.5 & VAL33 & GLN459, TYR475 & $3.46645,2.45612$ \\
\hline 6 & -6.2 & VAL33, VAL36 & TYR32 & 3.46645 \\
\hline 7 & -6.8 & $\begin{array}{l}\text { VAL33, PHE441, TYR32, } \\
\text { VAL33, VAL36, VAL473 }\end{array}$ & $\begin{array}{l}\text { GLN459, TYR475, ASN447, } \\
\text { GLN459, TYR32, VAL33, } \\
\text { ASN447 }\end{array}$ & $\begin{array}{l}2.74128,2.25213,2.17978, \\
2.34229,2.34106,3.27259,3.54378\end{array}$ \\
\hline 8 & -6.8 & TYR32, PHE441, VAL473 & GLN471, GLN471, VAL473 & $2.78717,2.49356,1.95694$ \\
\hline
\end{tabular}




\begin{tabular}{|c|c|c|c|c|}
\hline 9 & -5.8 & VAL473 & GLN471 & 1.890972 \\
\hline 10 & -6.8 & $\begin{array}{l}\text { TYR32, VAL33, VAL36, } \\
\text { VAL473 }\end{array}$ & $\begin{array}{l}\text { GLN459, TYR475, PRO446, } \\
\text { TYR32 }\end{array}$ & $2.70504,2.14216,2.52363,2.31888$ \\
\hline 11 & -6.4 & $\begin{array}{l}\text { TYR32, VAL33, VAL36, } \\
\text { VAL473 }\end{array}$ & GLN471, VAL473, TYR32 & $2.20088,2.32326,3.68108$ \\
\hline 12 & -8.2 & $\begin{array}{l}\text { PHE441, TYR32, VAL33, } \\
\text { VAL36, VAL473 }\end{array}$ & $\begin{array}{l}\text { GLN471, VAL473, VAL473, } \\
\text { VAL473 }\end{array}$ & $2.16237,2.28406,2.48848,3.7908$ \\
\hline 13 & -6.4 & $\begin{array}{l}\text { PHE441, TYR32, LYS445, } \\
\text { VAL33, VAL33, VAL473 }\end{array}$ & $\begin{array}{l}\text { GLN459, TYR475, PRO446, } \\
\text { TYR32, ASN447 }\end{array}$ & $\begin{array}{l}2.63885,1.91135,2.74706, \\
2.78744,3.40093\end{array}$ \\
\hline 14 & -6.5 & $\begin{array}{l}\text { PHE441, PHE441, TYR32, } \\
\text { VAL473, TYR32, LYS445 }\end{array}$ & VAL473 & 3.5723 \\
\hline 15 & -6.7 & $\begin{array}{l}\text { TYR32, LYS445, VAL33, } \\
\text { VAL36, VAL473 }\end{array}$ & PRO446, ASN447 & $2.73013,2.19031$ \\
\hline 16 & -6.9 & $\begin{array}{l}\text { PHE441, TYR32, VAL33, } \\
\text { VAL33, VAL36, VAL33, } \\
\text { VAL473 }\end{array}$ & TYR475, PRO446, ASN447 & $1.8843,2.70931,3.42094$ \\
\hline 17 & -6.4 & $\begin{array}{l}\text { ALA37, LEU13, VAL36 ALA16, } \\
\text { VAL33, ALA37, ILE568 }\end{array}$ & GLN471 & 2.08853 \\
\hline $18^{*}$ & -8.5 & $\begin{array}{l}\text { PHE441, MET12, TYR32, } \\
\text { VAL33, VAL36, VAL473, } \\
\text { VAL33, ALA16 }\end{array}$ & $\begin{array}{l}\text { TYR475, GLN459, TYR32, } \\
\text { ASN447 }\end{array}$ & $2.99272,2.80286,2.91539,3.10657$ \\
\hline $19 *$ & -8.3 & $\begin{array}{l}\text { PHE441, VAL33, VAL473, } \\
\text { LYS445 }\end{array}$ & ALA37, LYS445, TYR32 & $2.67588,2.11689,3.59539$ \\
\hline 20 & -6.7 & $\begin{array}{l}\text { PHE441, TYR32, VAL33, } \\
\text { VAL473 }\end{array}$ & $\begin{array}{l}\text { GLN459, TYR475, LYS445, } \\
\text { TYR32, ASN447 }\end{array}$ & $\begin{array}{l}2.75511,1.86745,2.16882,2.3693, \\
3.25999\end{array}$ \\
\hline 21 & -6.4 & PHE441, PHE441, LYS445 & LYS445, VAL473 & $2.06044,2.44172$ \\
\hline 22 & -6.8 & $\begin{array}{l}\text { ALA169, CYS321, HIS322, } \\
\text { CYS321 }\end{array}$ & $\begin{array}{l}\text { NI3001, NI3002, GLY279, } \\
\text { NI3002, ALA169 }\end{array}$ & $\begin{array}{l}2.18139,3.07181,2.33945, \\
2.09349,2.833\end{array}$ \\
\hline 23 & -8 & PHE441, LYS445, LYS445 & VAL473, LYS445 & $2.0024,3.45577,2.47638$ \\
\hline 24 & -7.7 & PHE441, LYS445 & VAL473, LYS445 & $2.22512,2.63733$ \\
\hline
\end{tabular}






Figure 5a - Visualization of 3D interaction between the ligand 18 and 1E9Y.

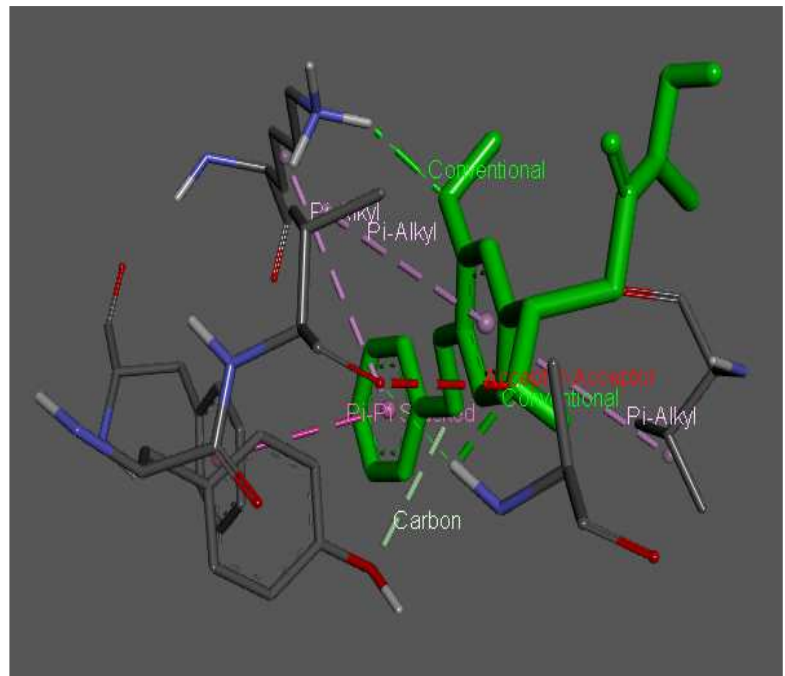

Figure 6a - Visualization of 3D interaction between protein enzyme 1E9Y ligand 19.
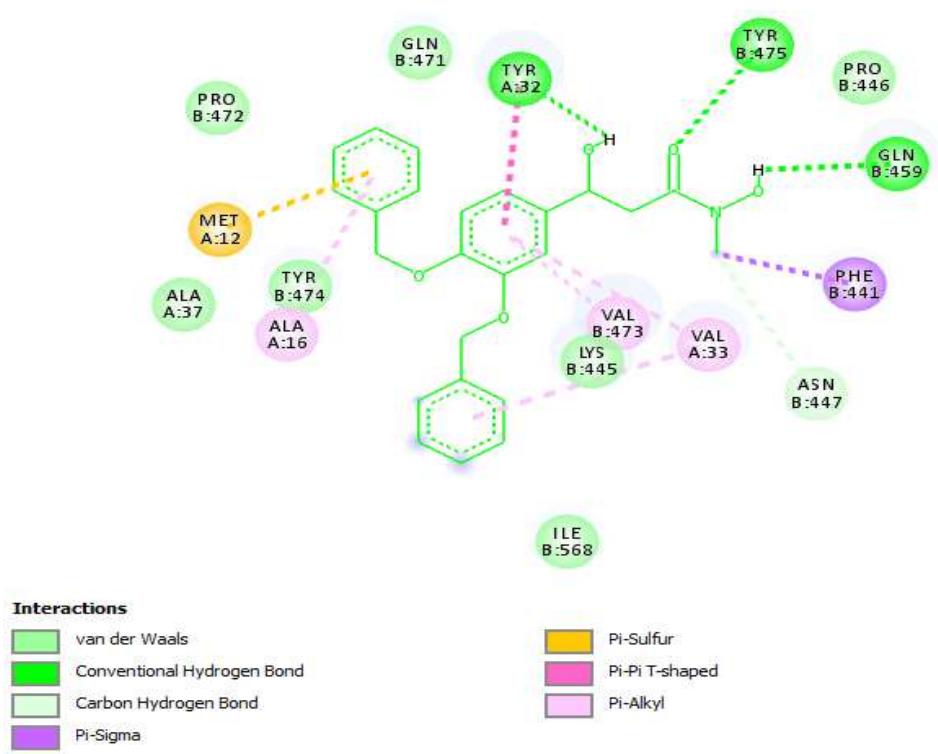

Figure 5b - 2D interaction between ligand 18 and 1E9Y receptor.

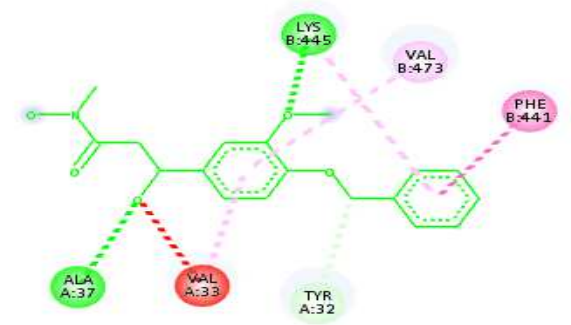

Interactions

Interactions
Conventional Hydrogen Bond

Carbon Hydrogen Bond

Unfavorable Acceptor-Acceptor

PiPi Stacked

$\square$ Pi-Alkyl

Figure 6b - 2D interactions between ligand 19 and 1E9Y receptor. 


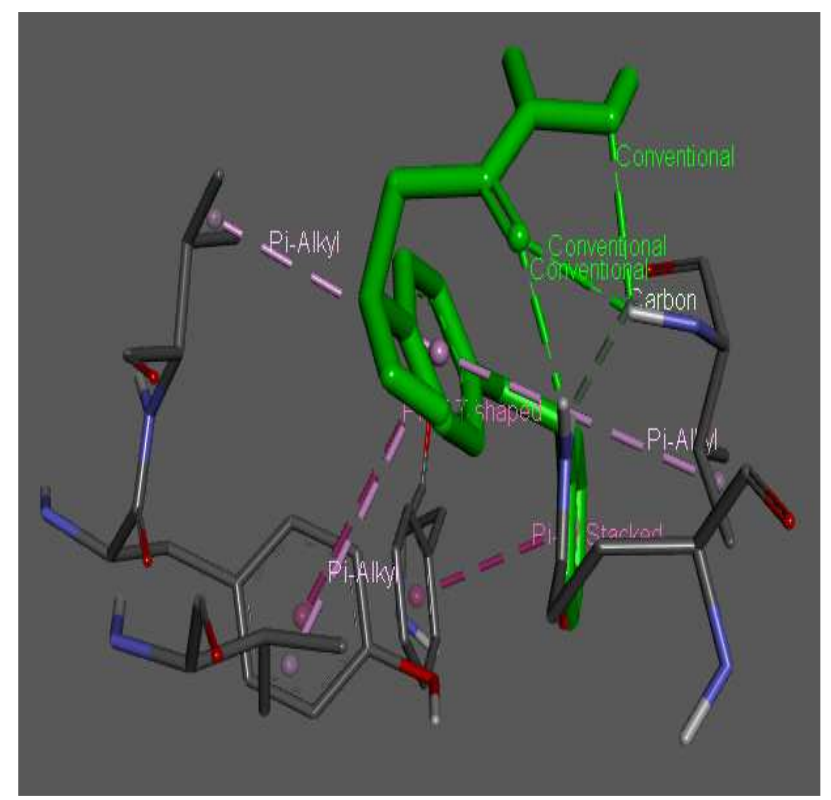

Figure 7a. Visualization of 3D Interaction between ligand 12 and 1E9Y receptor.

The above figures $5 \mathrm{a}-7 \mathrm{~b}$ shows three dimensional structures docked ligand and protein enzyme of 1E9Y complex. The result shows the best three ligand complex structures. Figure (5a) interaction between protein enzyme 1E9Y and ligand $18 \mathrm{x}$, figure (6a) interaction between 1E9Y protein enzyme and ligand $19 \mathrm{y}$ and lastly figure (7a) interaction between protein enzyme 1E9Y and ligand $12 x$. Figures $5 b, 6 b$ and $7 b$ are the $2 \mathrm{D}$ interactions structure of $3 \mathrm{D}$ which shows dark green dashed indicates conventional hydrogen bond, light green dashed shows carbon hydrogen bond and remaining dashes purple indicates hydrophobic interaction of each best three complex structures.

\subsection{Molecular Docking approach}

Molecular docking approach were carried out between the receptor (target) 1E9Y which is stationary and inhibitors ligand as mobile. All the compound candidates were found to be powerfully inhibitors by lodging the active site cavity, the interaction between protein receptor and ligands shows higher docking score with low energy values, the molecular docking result, binding energies value range from -5.8 $\mathrm{kcal} / \mathrm{mol}$ to $-8.5 \mathrm{kcal} / \mathrm{mol}$. All the antiulcer inhibitors compound (table 5) were found to be involved in both hydrophobic residue and hydrogen bond interaction and also shown the bond distance between the interactions. Molecular docking result of molecule $18 x$ shows better binding affinity score with the energy of $-8.5 \mathrm{kcal} / \mathrm{mol}$ than the other coligands, so its described as a novel lead candidate.

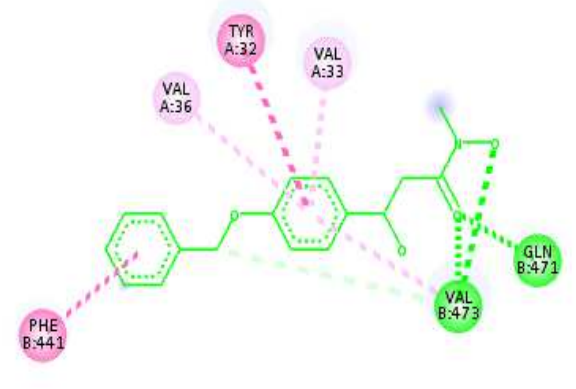

Interactions
Conventional Hydrogen Bond
$\square$ Carbon Hydrogen Bond
PiPi Stacked

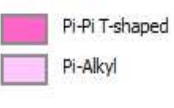

Figure 7b. 2D Interaction structure between ligand 12 and 1E9Y receptor.

\subsection{Binding mode of inhibitors}

The results shown (Table 5) best three docking score, out of 24 ligands presented in this paragraph, hydrogen bond distance and interacting hydrophobic residues are involved in the molecular docking of inhibitors molecules at the active site cavity of the protein receptor (1E9Y). Ligand number 12 shows clear of PHE441, TYR32, VAL33, VAL36 and VAL473 residues of goals target which are involved in hydrophobic residue interactions and four conventional hydrogen bond interactions of GLN471 - 2.16237, VAL473 3.7908 , VAL437 - 2.28406, VAL437 - 2.48848 with bond distance respectively. It was also showing the interactions ligand 19, the result of interaction residues of PHE441, VAL33, VAL473, LYS445 and three hydrogen interactions of ALA37, LYS445, TYR32 with the bond distance of (2.67588 $\AA, 2.11689 \AA, 3.59539 \AA$ ) were obtained. Ligand 18 (best docking scores) of $-8.5 \mathrm{kcal} / \mathrm{mol}$ formed TYR475, GLN459, TYR32 and ASN447 with bond distance of (2.99272 А, $2.80286 \AA, 2.91539 \AA$ \& $3.10657 \AA$ ) and eight hydrophobic interaction residues of PHE441, MET12, TYR32, VAL33, VAL36, VAL473, VAL33, ALA16, this shows that even the number of residue interactions is greater than in the remaining ligand 12 and 19 respectively.

\section{CONCLUSION}

It has been clear and distinct that, the steps used in this research was successfully in finding the best candidate inhibitor for peptic ulcer, by the used of dataset from In silico approach. Significant correlation coefficients of determinations found to be $R^{2}=0.9989$ with the enzyme inhibiting activity and this achieved by the used of quantum chemical descriptors or physicochemical descriptors to 
obtain the model. Out of 24 compounds, ligand $18 x$ found to have higher binding energy with a molecular docking score of $-8.5 \mathrm{kcal} / \mathrm{mol}$ against their protein receptor (1E9Y) and predicted activity value number of 3.45 in the exercise of QSAR. Candidate (ligand) 18x was docked within pocket region cavity, forming four different hydrogen bond interactions of TYR475, GLN459, TYR32, ASN447 and eight hydrophobic region interactions of PHE441, MET12, TYR32, VAL33, VAL36, VAL473, VAL33 and ALA16 (active site), both the two interaction shows in the cavity of protein receptor (1E9Y), in this juncture, the result shows better binding energy than the others.

This research shows that, excellent agreement between molecular docking combined with results of computational approach simulations and experimental affinities of hydroxamic acid derivatives and apparent. This agreement of studies on In-silico approach and experimental results suggests that, the docking exercise and other parameters may be useful and be a valuable tool in design for a new novel antiulcer drug candidate.

\section{REFERENCES}

Abdulfatai, U., Uzairu, A., Uba, S., \& Shallangwa, G. A. (2019). Molecular modelling and design of lubricant additives and their molecular dynamic simulations studies of Diamond-Like-Carbon (DLC) and steel surface coating. Egyptian Journal of Petroleum, 28(1), 111-115.

Amtul Z, Siddiqui RA, Choudhary MI, Chemistry and mechanism of urease in- hibition. Curr Med Chem 2002 9:1323-48

Chey, W.; Chathadi, K.; Montague, J.; Ahmed, F.; Murthy, $\mathrm{U}$. Intragastric acidification reduces the occurrence of false-negative urea breath test results in patients taking a proton pump inhibitor. Am. J. Gastroent. 2001; 96(4): 1028-32.; Hunter, P. Where next for antibiotics? The immune system and the nature of pathogenicity are providing vital clues in the fight against antibiotic-resistant bacteria. EMBO Rep. 2012; 13: 680-3.

Ezealisiji KM, Ijeomah SC, Agbo MO, Anti-ulcer activity of African walnut Tetracarpidium conophorum nuts against gastric ulcers in rats. Asian Pac J Trop Dis 2014 4:998-1001

Hugo Kubinyi. Applications of Hansch Analysis.; QSAR, Hanch Analysis and Related Approaches VCH 1993, 5-(6), 567

Jitender K. Malik, Himesh S.; Singhai AK,; Harish P.; hydroxamic acids as Helicobacter pylori urease inhibitors, International Journal of Phermaceutical Research \& Allies Science 2013, Feb 2; 2, 1

Kennard RW, Stone LA. Computer aided design of experiments, Journal of Technometrics 1969, Sep 7; 11(1):137-48.

Khaled KF. Modeling corrosion inhibition of iron in acid medium by genetic function approximation method: a QSAR model. Journal of Corro Sci 2011; 53(11):3457-65

Kosikowska, P.; Berlicki, Ł. Expert opinion on therapeutic patents, 2011 Augt 6, 21: 945
Kubinyi, H. (1993). QSAR Hanch Analysis \& Related ApproachES. In H. Kubinyi. Tokyo, Japan: VCH, New York, USA.

Kubo, J.; Lee, J. R.; Kubo, I. Anti-Helicobacter pylori Agents from the Cashew Apple, Journal of Agricultural and Food Chemistry 1999, Jun 6, 47, 533

Kumar DB, Kumar PV, Bhubaneswaran SP, Mitra A. Advanced drug designing softwares and their application in medical research. Int J Pharm Sci 2010 Apr 23; 2:16-8.

Mallesha*b and Hua-Li Qin*a et al, Synthesis and molecular docking studies of xanthone attached amino acids as potential antimicrobial and anti-inflammatory agents, J. MedChemComm, 2017 Aug 1; 8(8): 1706-1719.

Monika JK, Singh K. Virtual screening using the ligand ZINC database for novel lipoxygenase-3 inhibitors. Bioinformation. 2013; 9(11):583.

Neelarapu, R.; Holzle, DL.; Velaparthi, S.; Bai, H.; Brunsteiner, M.; Blond, S. Y.; Petukhov, P. J. Synthesis, molecular docking and kinetic properties of $\beta$-hydroxy- $\beta$-phenylpropionyl-hydroxamic acids as Helicobacter pylori urease inhibitors, European journal of medicinal chemistry 2013 Aug 9, 68: 212.

Puzyn, J. L. challenges and advances in computational chemistry and physics tomasz. in recent advances in qsar studies. London, New York: springer dordrecht heidelberg. 2010. feb 3 (vol. 8, pp. 5-7).

Radin JN, González-Rivera C, Frick-Cheng AE, Sheng J, Gaddy JA, Rubin DH, Scott Algood HM, McClain MS, Cover TL. Role of connexin 43 in Helicobacter pylori VacA-induced cell death. J. Infect. Immun. 2013; 82: 423-32.

Ravinchandran R.; V., Jain., H.; Sivansan.; A.; VargheseS.; Kishore, Agrawal.; R.; Characterization of pioglitazone cyclodextrin complexes Int. J. of Drug Design and Discov, 2011, Nov. 7.; 2:511-519

Ravinchandran Rajak V, Jain H, Sivadasan A, Varghese S, Kishore-Agrawal CP. Quantitative structure-activity relationship (QSAR) for predicting the anticonvulsant activity of $\alpha \_$substituted acetamido-Nbenzylacetamide derivatives R Int J Drug Des Discov 2011 Apr 16;2:511-9.

Sachs G, Weeks DL, Wen Y, Marcus EA, Scott DR, Melchers K. Acid acclimation by Helicobacter pylori. Physiology (Bethesda). 2005; 20: 429-38.

Saeed A, Tehseen Y, Rafique H, Furtmann N, Bajorath J. Benzothiazolyl substituted iminothiazolidinones and benzamido-oxothiazolidines as potent and partly selective aldose reductase inhibitors. Med. Chem. Commun. 2014; 5: 1371-80; Azizian H, Nabati F, Sharifi A, Siavoshi F, Mahdavi M, Amanlou M. Large-scale virtual screening for the identification of new Helicobacter pylori urease inhibitor scaffolds. J. Mol. Model. 2012; 18: 2917-27.

Sharma D, Bhatt SA, Comprehensive review on ulcer healing potential of medicinal plants. Int $\mathrm{J}$ Pharm Pharm Sci 2014 6:10

Simmons, K. J.; Chopra, I.; Fishwick, C. W. Structure-based discovery of antibacterial drugs. Nature Reviews Microbiology. 2010; 501-10.; Lodhi MA, Nawaz SA, Iqbal S, Khan KM, Rode BM, Choudhary MI. 3DQSAR CoMFA studies on bis-coumarine analogues as 
urease inhibitors: A strategic design in anti-urease agents. Bioorg. Med. Chem. 2008; 16(6): 3456-61.

Stingl K, Altendorf K, Bakker EP. Acid survival of Helicobacter pylori: how does urease activity trigger cytoplasmic $\mathrm{pH}$ homeostasis? Trends in microbiol. 2002; 10(2): 70-4; Maroney MJ, Ciurli S. Nonredox Nickel Enzymes. Chem. Rev. 2013; 114(8): 4206-28.

Trott O, Olson AJ. AutoDock Vina: improving the speed and accuracy of docking with a new scoring function, efficient optimization, and multithreading. J Comput Chem 2010 Jun 5; 31:455-61.

Wang, X. D.; Wei, W.; Wang, P. F.; Yi, L. C.; Shi, W. K.; Xie, Y. X.; Synthesis, and evaluation of novel fluoroquinoloneeflavonoid hybrids as potent antibiotics against drug-resistant microorganisms, J. Bioorganic \& medicinal chemistry 2015, Oct 20, 23: 4860

Wang, X. D.; Wei, W.; Wang, P. F.; Yi, L. C.; Shi, W. K.; Xie, Y. X.; Wu, L. Z.; Tang, N.; Zhu, L. S.; Peng, J. Synthesis, molecular docking and biological evaluation of 3-arylfuran-2(5H)-ones as anti-gastric ulcer agent. Bioorganic \& medicinal chemistry 2015, Aug 1. 23, 4860

Xiao, Z. P.; Peng, Z. Y.; Dong, J. J.; He, J.; Ouyang, H.; Feng, Y. T.; Lu, C. L.; Lin, W. Q.; Wang, J.X.; Xiang, Y. P.; Structure-activity relationship analysis and kinetics study of reductive derivatives of flavonoids as Helicobacter pylori urease inhibitors. European journal of medicinal chemistry 2013 May; 63:685-95. Peng, Z. Y.; Wang, X. D.; Feng, Y. T.; He, J.; Xiao,
Z. P.; Biological evaluation and molecular modeling of 1,3,4-thiadiazol-2-amide derivatives as novel antitubulin agents. Journal of Jishou University (Natural Sciences Edition) 2012, Jun 6, 021

Xiao, Z. P.; Shi, D. H.; Li, H. Q.; Zhang, L. N.; Xu, C.; Zhu, H. L. Polyphenols based on isoflavones as inhibitors of Helicobacter pylori urease. Bioorganic \& medicinal chemistry. 2007 Jun 1; 15(11): 3703-10.

Xiao, Z. P.; Wang, X. D.; Peng, Z. Y.; Huang, S.; Yang, P.; Li, Q. S.; Zhou, L. H.; Hu, X. J.; Wu, L. J.; Zhou, Y. Dilatational Rheology of Heat-Treated Soy Protein at the Oil-Water Interface: Relationship to Structural Properties, Journal of agricultural and food chemistry 2012, Nov 1 60: 10572.

Yamasaki E, Wada A, Kumatori A, et al. Helicobacter pylori vacuolating cytotoxin induces activation of the proapoptotic proteins Bax and Bak, leading to cytochrome $\mathrm{c}$ release and cell death, independent of vacuolation. J Biol Chem 2006 281: 11250-11259

Yap CW. PaDEL-descriptor: open source software to calculate molecular descriptors and ingerprints. J Comput Chem 2011 Jul 9; 32 (7):1466-74.

Zhang, Y.; Feng, J.; Jia, Y.; Wang, X.; Zhang, L.; Liu, C.; Fang, H.; $\mathrm{Xu}, \quad \mathrm{W}$. Development of Tetrahydroisoquinoline-Based Hydroxamic Acid Derivatives: Potent Histone Deacetylase Inhibitors with Marked in Vitro and in Vivo Antitumor Activities Journal of medicinal chemistry, 2011 Apr 5, 54: 2823 